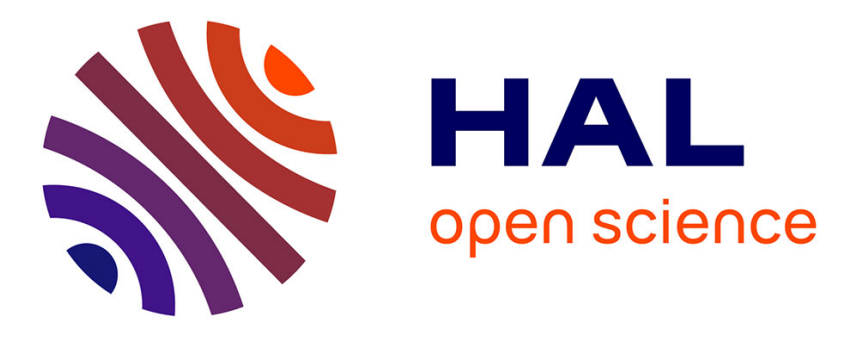

\title{
Real-Time NMR Studies of Electrochemical Double-Layer Capacitors
}

Hao Wang, Thomas K.-J. Köster, Nicole M. Trease, Julie Segalini, Pierre-Louis Taberna, Patrice Simon, Yury Gogotsi, Clare P. Grey

\section{- To cite this version:}

Hao Wang, Thomas K.-J. Köster, Nicole M. Trease, Julie Segalini, Pierre-Louis Taberna, et al.. RealTime NMR Studies of Electrochemical Double-Layer Capacitors. Journal of the American Chemical Society, 2011, vol. 133 ( $\mathrm{n}^{\circ}$ 48), pp. 19270-19273. 10.1021/ja2072115 . hal-01151679

\author{
HAL Id: hal-01151679 \\ https://hal.science/hal-01151679
}

Submitted on 13 May 2015

HAL is a multi-disciplinary open access archive for the deposit and dissemination of scientific research documents, whether they are published or not. The documents may come from teaching and research institutions in France or abroad, or from public or private research centers.
L'archive ouverte pluridisciplinaire HAL, est destinée au dépôt et à la diffusion de documents scientifiques de niveau recherche, publiés ou non, émanant des établissements d'enseignement et de recherche français ou étrangers, des laboratoires publics ou privés. 


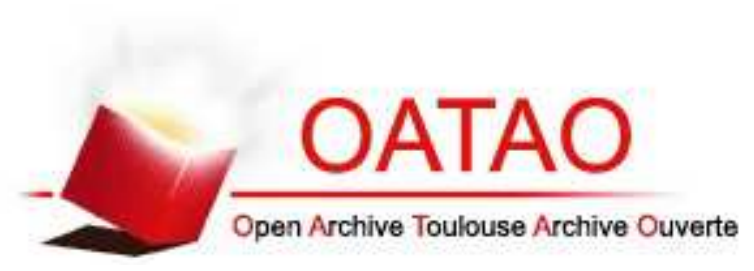

\section{Open Archive TOULOUSE Archive Ouverte (OATAO)}

OATAO is an open access repository that collects the work of Toulouse researchers and makes it freely available over the web where possible.

This is an author-deposited version published in : http://oatao.univ-toulouse.fr/ Eprints ID : 13889

To link to this article : DOI:10.1021/ja2072115

URL : http://dx.doi.org/10.1021/ja2072115

\section{To cite this version :}

Wang, Hao and Köster, Thomas K.-J. and Trease, Nicole M. and Segalini, Julie and Taberna, Pierre-Louis and Simon, Patrice and Gogotsi, Yury and Grey, Clare P. Real-Time NMR Studies of Electrochemical Double-Layer Capacitors. (2011) Journal of the American Chemical Society, vol. 133 (n 48). pp. 19270-19273. ISSN 0002-7863

Any correspondance concerning this service should be sent to the repository administrator: staff-oatao@listes-diff.inp-toulouse.fr 


\title{
Real-Time NMR Studies of Electrochemical Double Layer Capaci- tors
}

\author{
Hao Wang ${ }^{1,2}$, Thomas K.-J. Köster ${ }^{1,2}$, Nicole M. Trease ${ }^{2}$, Julie Ségalini ${ }^{3}$, Pierre-Louis Taberna ${ }^{3}$, Patrice Simon $^{3}$, \\ Yury Gogotsi ${ }^{4}$, Clare P. Grey ${ }^{* 1,2}$ \\ 1.University of Cambridge, Department of Chemistry, Lensfield Road, Cambridge CB2 1EW, UK \\ 2. Stony Brook University, Department of Chemistry, Stony Brook, NY 11794-3400, USA \\ 3. Université Paul Sabatier, CIRIMAT, UM-CNRS 5085, F-31062 Toulouse, France
}

4. Drexel University, Department of Material Science \& Engineering, Philadelphia, PA 19104, USA

KEYWORDS. In situ NMR, sorption, carbon, supercapacitors

\begin{abstract}
B}$ NMR spectroscopy has been used to investigate the sorption of $\mathrm{BF}_{4}^{-}$anions on a highly porous, high surface area carbon and different binding sites were identified. By implementing in situ NMR approaches, the migration of ions between the electrodes of the supercapacitors, and the changes in nature of ion binding to the surface have been observed in real-time.
\end{abstract}

Over the last several decades, the demand for energy has increased dramatically. With the increased use of renewable energy sources comes the challenge as to how energy can be stored and converted. ${ }^{1,2}$ Both batteries and supercapacitors show great potential as electrical energy storage devices. Although batteries show higher energy densities, they have lower power handling abilities and shorter cycle lives. ${ }^{3}$ Since the 1980s, Electrochemical Double Layer Capacitors (EDLCs or supercapacitors) have been developed to meet this demand, due to their extremely rapid rates of charge and discharge, and their essentially unlimited cycle life. ${ }^{4}$ The storage of electrical energy in supercapacitors relies on the formation of an electrochemical double layer on the interface between a solid electrode and a liquid electrolyte solution. Upon charging, energy is stored as the cations and anions are electrostatically attracted to different electrodes, forming the double layers. Among all potential materials for supercapacitors, carbon has been widely used as the electrode, because of its high porosity, good electronic conductivity and low $\operatorname{cost}^{5}$ The porosity of carbon is crucial because it increases the effective surface area. ${ }^{6}$ Furthermore, in 2006 Chmiola et al. reported that the normalized capacitance of carbon derived from titanium carbide dramatically increased when the average size of carbon pores matched the size of the solvated ion. ${ }^{7}$ This finding could not be explained with traditional concepts of double layer formation and have triggered considerable work to understand the nature of electrolyte sorption inside the carbon. Many questions concerning this process remain unsolved. ${ }^{5,8,9}$ Desolvation of ions has been experimentally demonstrated using in situ Quartz Micro-balance (QCM) measurements while charging porous carbon electrodes. ${ }^{10}$ In principle, NMR spectroscopy can help to unravel the different processes that occur at the electrodes in supercapacitors, as it provides molecular-level, quantitative, and element-selective information about the structure and dynamics of the ions in the electrolyte and at the electrolyte electrode interface. Indeed, in situ NMR has, for example, been used to look at the adsorption of methanol (and electrochemically produced $\mathrm{CO}$ and $\mathrm{CO}_{2}$ ) on $\mathrm{Pt}$ fuel-cell electrodes as a function of potential and to investigate dynamic and structural processes in lithium ion batteries. ${ }^{11-15}$

Previous ex situ magic angle spinning (MAS) NMR experiments have been conducted on carbon-based supercapacitors made with a tetraethylammonium $\left(\mathrm{TEA}^{+}\right)$tetrafluoroborate $\left(\mathrm{BF}_{4}^{-}\right)$ salt in acetonitrile as the electrolyte. In these experiments, the supercapacitors were disassembled at different charge/discharge states, and ${ }^{11} \mathrm{~B}$ NMR spectra were separately acquired for the cathode and the anode. ${ }^{16,17}$ Although providing useful information, questions remain concerning the possibility of discharging the electrodes during the process of disassembly, and the changes in binding that arise due to the inevitable evaporation of the solvent. To overcome these limitations, we have applied in situ NMR experiments on supercapacitors for the first time. In situ NMR experiments not only allow the changes in local environments of the ions in the carbon electrodes in real time to be tracked, but also allow the dynamics of the different process that occur on changing the potential to be monitored. ${ }^{14,18}$ This paper reports results from these studies, focusing on the behavior of the $\mathrm{BF}_{4}^{-}$ anion. As in previous studies, we chose to focus the majority of our studies on ${ }^{11} \mathrm{~B}$ rather than ${ }^{19} \mathrm{~F}$ NMR, since the electrodes comprise a composite mixture of carbon and polytetrafluoroethylene (PTFE).

First, to investigate the possible environments of the $\mathrm{BF}_{4}{ }^{-}$anions on the surface of uncharged carbon electrodes (in the supercapacitor system), sorption studies were performed. ${ }^{11} \mathrm{~B}$ NMR spectra were acquired for carbon films of YP-17 (specific surface area $1709 \mathrm{~m}^{2} / \mathrm{g}$ ), which were soaked with different amounts of $1.5 \mathrm{M} \mathrm{TEA}-\mathrm{BF}_{4}$ in acetonitrile (Figure 1; see supporting information for more details). We performed static experiments rather than MAS, since the centrifugal forces in the spinning caused electrolyte to be extruded from the carbon pores. No significant losses in spectral resolution were observed. Three different environments were identified: for low electrolyte loadings $(2 \mu \mathrm{L}$ electrolyte; $6.1 \mathrm{mg}$ of YP-17), a broad peak appears at $-4.2 \mathrm{ppm}$, which is ascribed to strongly bound $\mathrm{BF}_{4}^{-}$ions on the carbon surfaces. As more electrolyte is added, a second peak appears at higher frequencies (approximately $1.7 \mathrm{ppm}$ with $5 \mu \mathrm{L}$ ), which is ascribed to ions that are only weakly affected by the carbon, i.e., the weakly bound ions in the outer sorption layers and/or ions contained within the larger mesopores, which will be in dynamic exchange with the ions in the outer sorption layers. Exchange occurs between the strongly (lower frequency resonances) and the weakly bound ions (higher frequency resonances) on the timescale of approximately $50-500 \mathrm{~ms}$, as shown by twodimensional (2D), magnetization exchange experiments (Figure S17) confirming that the weakly bound ions are in close proximity to the strongly bound ions. Both peaks shift slightly to higher frequency as more electrolyte is added reaching -1.7 and $4.3 \mathrm{ppm}$ for $10 \mu \mathrm{L}$ of electrolyte. Finally, three peaks $(-1.7,4.3$ and 0.6 ppm) were observed when the film was fully soaked with electrolyte $(15 \mu \mathrm{L})$. The third peak (sharp, $0.6 \mathrm{ppm}$ ), which only appears at the highest electrolyte levels, is ascribed to free ions in the bulk electrolyte that are not contained within the carbon pores. These 
assignments are consistent with earlier studies that find that free molecules (i.e., in the bulk electrolyte) are associated with higher chemical shifts than molecules adsorbed onto the surface of carbon. ${ }^{19}$ Following these studies, the shifts for the adsorbed species are ascribed to the magnetic susceptibility of the carbon and aromatic "ring-current" effects due to the carbon rings of the graphitic domains. Consistent with this assignment, is the observation (in a separate set of sorption experiments; Figure S8 and S11) of a set of lower frequency resonances (relative to the positions of the resonances of the weakly bound/free electrolyte peaks) when TEA-BF ${ }_{4}$ sorption is probed with ${ }^{19} \mathrm{~F}$ NMR (for the anions), and with ${ }^{1} \mathrm{H}$ NMR for the TEA cations, confirming that this is local field affect rather than a chemical one due chemisorption. The previous studies of molecules adsorbed on carbons have similarly seen a shift of the resonance of the adsorbed species to higher frequencies as the loading level is increased, where the shift was ascribed to the exchange of ions in close proximity of the carbon surface with ions in outer layers. ${ }^{19,20}$ It is, however, important to note that the size of the shift seen in our studies as a function of sorption level varies somewhat depending on the orientation of the film in the field and the geometry of the bag, and these variations are, at least in part ascribed to macroscopic susceptibility effects (see supporting information). ${ }^{21}$

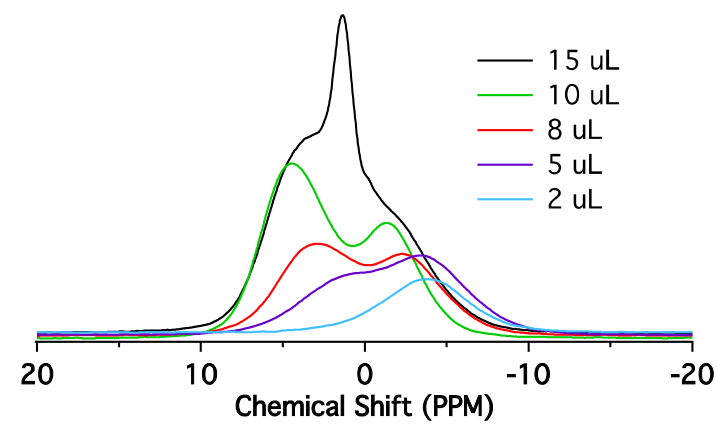

Figure 1. ${ }^{11} \mathrm{~B}$ NMR spectra of YP-17 carbon films with different amounts of $1.5 \mathrm{M}$ TEA-BF 4 in acetonitrile in plastic bags.

Based on the intensities of the peak assigned to the strongly bound ions in the 10 and $15 \mu \mathrm{L}$ sorption experiments we can estimate packing densities of approximately 0.37 and 0.53 ani$\mathrm{ons} / \mathrm{nm}^{2}$, respectively, if we assume the ions are uniformly packed on the carbon surface (see supporting information). These numbers should be compared with the diameter of a solvated $\mathrm{BF}_{4}^{-}$of $1.16 \mathrm{~nm}^{22}$. Assuming that the fully solvated $\mathrm{BF}_{4}^{-}$anions are close packed on the carbon surface $\left(1709 \mathrm{~m}^{2} / \mathrm{g}\right)$, the highest possible density of solvated anions is 0.86 anions $/ \mathrm{nm}^{2}$. This calculation ignores the effect of the cations. To include them, we consider a centered cubic lattice formed of $1.30 \mathrm{~nm}$ cations and $1.16 \mathrm{~nm}$ anions (Figure S1), the centered lattice having a cell parameter of $2.46 \mathrm{~nm}(1.30+1.16 \mathrm{~nm})$. A packing density of 0.33 anions $/ \mathrm{nm}^{2}$ is predicted. Numbers estimated in a separate sorption experiment for both the anions and cations are similar, but with very slightly more strongly bound cations than anions (see supporting information). Our estimates for the ion packing density are consistent with a high density of solvated cations and anions on the surfaces of the carbons and are surprisingly high given the curvatures and small nanometer sizes of many of the carbon pores (see below).

Previous sorption studies found that the spin-lattice $\left(T_{1}\right)$ relaxation times are significantly reduced for molecules adsorbed on a carbon surface. ${ }^{23}$ In a separate sorption experiment with $20 \mu \mathrm{L}$ of electrolyte $/ 6.1 \mathrm{mg}$ carbon, a longer $\mathrm{T}_{1}$ value of $8.1 \mathrm{~s}$ was obtained for the free electrolyte, whereas shorter values are obtained for the signals of weakly and strongly bound ions (4.0 and $3.2 \mathrm{~s}$, respectively). The $T_{1}$ time of the resonance assigned to the weakly bound ions (in the mesopores) confirms that these ions are influ- enced by the carbon, and that the weakly bound resonance is not simply due to free electrolyte. The slow exchange between the two species (as probed by the 2D experiments) will, at least in part, be responsible for the reduction in $\mathrm{T}_{1}$ time of this resonance. The reduction of ${ }^{11} \mathrm{~B}$ spin lattice relaxation times near the carbon surface is ascribed to the interaction of the ${ }^{11} \mathrm{~B}$ nuclear spins with the fluctuating unpaired spins at the Fermi level of the carbon conduction band.

Having identified different types of binding for $\mathrm{BF}_{4}{ }^{-}$ions in carbon electrodes, the migration and binding of ions in an actual supercapacitor was followed by in situ NMR spectroscopy. In these experiments, the NMR spectra of a supercapacitor were measured under simultaneous control of its state of charge via an external cycler. To perform these experiments, a supercapacitor based on the flexible plastic bag cell design reported previously was developed $^{13,14}$ (Figure 2a; see supporting information). Two pieces of carbon film with the same weight $(11.2 \mathrm{mg} / \mathrm{each})$ were cut and pressed onto pieces of carbon coated aluminum mesh and a polypropylene separator was placed between them. This assembly was soaked with the $1.5 \mathrm{M}$ TEA-BF 4 in acetonitrile solution (approximately $50 \mu \mathrm{L}$ ) and was sealed inside a plastic bag in an argon atmosphere. In this design, which we refer to as "normal" in the following, the two electrodes are placed on top of each other. The bag cell was then put in the coil of the NMR probe, and connected with a cycler through the carbon coated aluminum mesh current collector (Figure S2). ${ }^{11} \mathrm{~B}$ in situ NMR spectra of this bag cell were acquired as a function of state of charge (Figure 3). At $0 \mathrm{~V}$, the spectrum is similar to the carbon soaked with TEA- $\mathrm{BF}_{4}$ solution. The free electrolyte peak is very weak, and the lineshape seen in the spectrum is intermediate between those of $6.1 \mathrm{mg}$ carbon with 10 and $15 \mu \mathrm{L}$ of TEA-BF 4 solution in Figure 1. Importantly, the results indicate that most of the $\mathrm{BF}_{4}{ }^{-}$ions are located in the vicinity of the carbon probably due to the limited volume of the plastic bags (and thus electrolyte). As the voltage increased from 0 to $2 \mathrm{~V}$, the high and low frequency peaks appear to merge, and at $2 \mathrm{~V}$, only one resonance, with a shoulder to lower frequency can be seen.
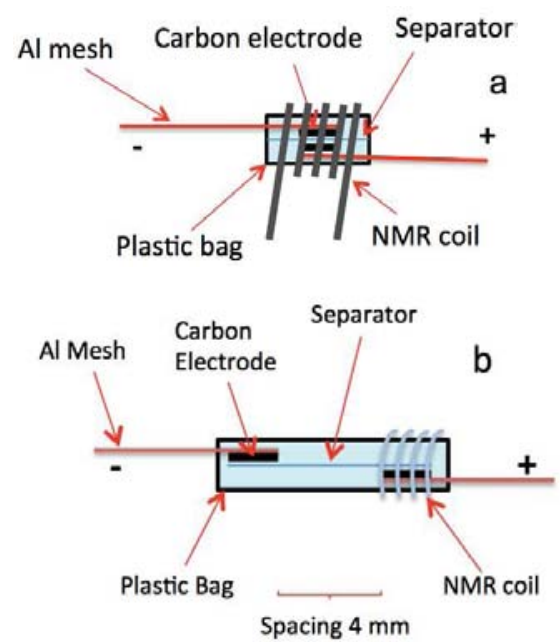

Figure 2. a: Configuration of a normal supercapacitor cell for in situ NMR study. b: Configuration of a "long" supercapacitor with two separated electrodes.

In the cell design described above (Figure 2a), NMR signals from both electrodes of the supercapacitor are investigated simultaneously and it is not clear how to separate the resonances associated with the different electrodes. To address this, a second design was used where the electrodes are no longer facing each other but rather are sheared so that they are separated by a $4 \mathrm{~mm}$ gap (Figure 2b). This configuration allows the NMR spectra of the 
individual electrodes to be monitored separately by placing only one electrode inside the NMR coil. The ${ }^{11} \mathrm{~B}$ in situ NMR spectra of the supercapacitor charged from 0 to $2 \mathrm{~V}$ and charged from 0 to $-2 \mathrm{~V}$ (Figure $4 \mathrm{a}-\mathrm{c}$ ) now show the individual spectra of the positive and negative electrodes. At $0 \mathrm{~V}$, the same three electrolyte features are again identified: the strongly bound ions, weakly bound ions and the free electrolyte. The free electrolyte peak is slightly more intense in this design, presumably because the larger bag used in this experiment means that more electrolyte can be added. As this resonance overlaps strongly with the weakly bound ion peak (i.e., from the ions nearby the carbon), its relative amount is difficult to quantify accurately. All the resonances are shifted by approximately $4.4 \mathrm{ppm}$ compared with the sorption study, including the free electrolyte peak, which we ascribe to bulk susceptibility effects associated with the orientation of the carbon and bag geometry (with respect to the magnetic field) used in this experiment, as discussed in the supporting information. As shown in the supporting information, small variations in the relative concentrations of the different peaks and their shifts are noted from experiment to experiment, but the results described here are consistent from one experiment to the next. Compared with the normal supercapacitors (Figure 3), the "long" capacitors require a much longer time for the current to reach equilibrium after the applied potential has been changed (see supporting information).

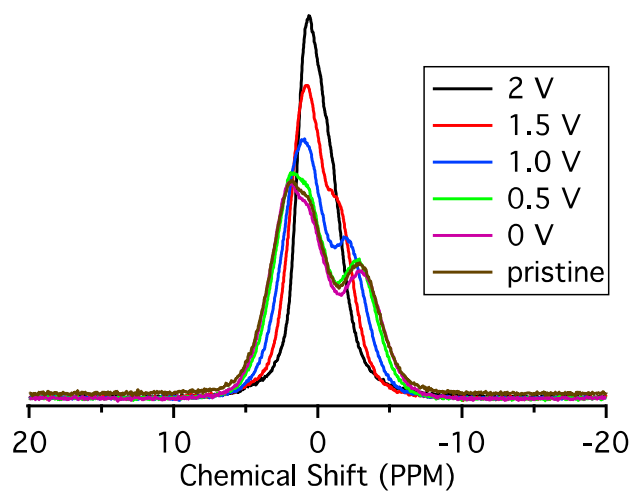

Figure 3. In situ ${ }^{11} \mathrm{~B}$ static NMR spectra of a normal YP-17 supercapacitor held at different voltages. In this experiment, both electrodes were placed inside the NMR coil as illustrated in Figure 2a.

On charging from 0 to $+2 \mathrm{~V}$, the signal at lower frequencies becomes narrower and moves to higher frequencies towards the peak that was previously assigned to the weakly bound ions (Figure 4a). This is consistent with the results of the normal cell design. The peak assigned to the weakly bound ions becomes narrower. A different behavior is observed when charging from 0 to $-2 \mathrm{~V}$ (Figure 4b). Most noticeable is the loss in intensity of the resonance due to the strongly bound ions (below $-0.5 \mathrm{~V}$ ) and its gradual shift to higher frequency. This resonance can no longer be observed at $-2 \mathrm{~V}$. Again the peak at higher frequencies becomes narrower but now also shifts to lower frequency, so that at $-2 \mathrm{~V}$ a sharper, more Lorentzian lineshape is observed. A plot of the total integrated signal intensity shows, as expected, a steady decrease in $\mathrm{BF}^{-}$concentration from $+2 \mathrm{~V}$ to $-2 \mathrm{~V}$.

$\mathrm{T}_{1}$ relaxation times were measured in a separate experiment. The spin lattice relaxation times of the strongly bound $\mathrm{BF}_{4}{ }^{-}$ions decrease from 2.1 to $0.3 \mathrm{~s}$ as the voltage was increased from -2 to $2 \mathrm{~V}$ (Figure 5). This noticeable decrease in relaxation time is assigned to increased anion-carbon interactions at positive potentials and possibly effects due to changes in the density of states at the Fermi level of carbon, due to injection of (positive) charge. It is also of note that the $T_{1}$ times of frequency signal represents an average of both environments). The weakly bound ions are af- fected by the applied voltage $(5.0 \mathrm{~s}$ at $-2 \mathrm{~V}, 0.5 \mathrm{~s}$ at $+2 \mathrm{~V})$, showing that the influence of the carbon on the relaxation behavior is not restricted to the first adsorbed layer, consistent with a slow exchange of the weakly bound ions with the strongly bound ions, in the timescale of the $\mathrm{T}_{1}$ experiment (i.e., $1-5 \mathrm{~s}$ ). (Note that we cannot unambiguously separate the signals of weakly bound and free ions, so the $T_{1}$ data for the high-frequency signal represents an average of both environments.
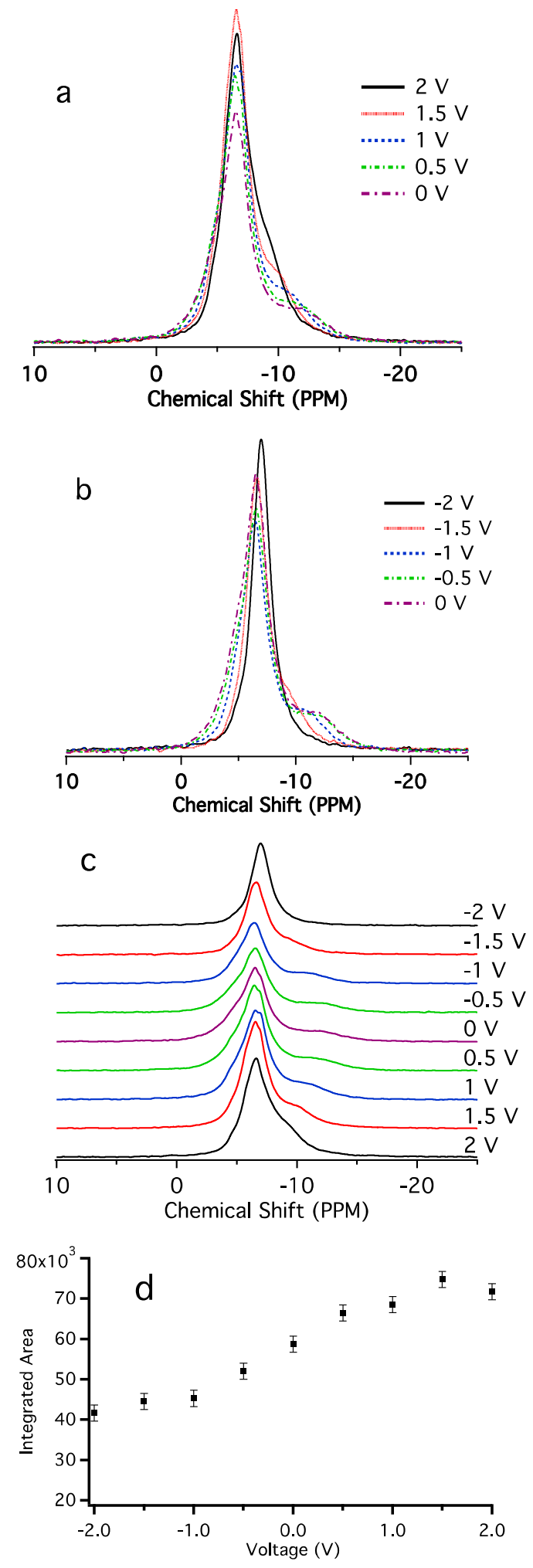
Figure 4. In situ ${ }^{11} \mathrm{~B}$ static NMR spectra of a"long" YP-17 supercapacitor held at different voltages. In these experiments, only one electrode is placed inside the NMR coil (see Figure 2b.) a: supercapacitor charged from 0 to $2 \mathrm{~V}$ (positive electrode). b: supercapacitor charged from 0 to $-2 \mathrm{~V}$ (negative electrode). c: stacked plot of Figure $4 \mathrm{a}$ and $4 \mathrm{~b}$. d: Integrated areas of the spectra in Figure $4 \mathrm{a}$ - $\mathrm{c}$ as a function of applied voltage.

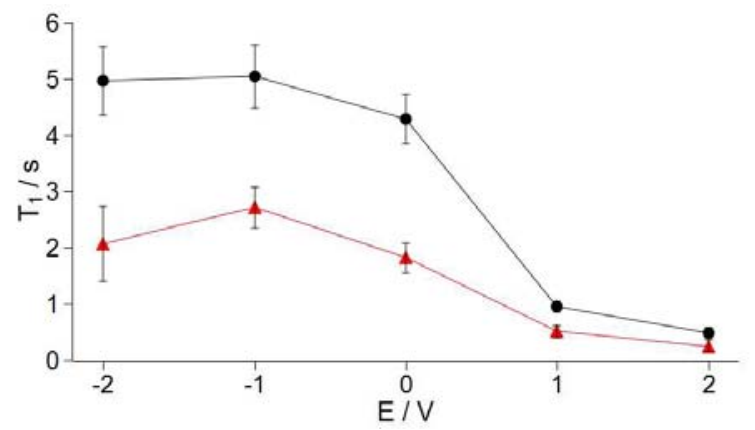

Figure 5. ${ }^{11} \mathrm{~B} \mathrm{~T}_{1}$ times for the "long" YP17 supercapacitor. Triangles and circles represent data for low-frequency (strongly bound anions) and high-frequency peaks (weakly bound and free ions), respectively.

The great majority of the BET "surface" of a high surface-area carbon actually arises from an internal "surface" and the outer surface of carbon particles can be neglected (less than $1 \%$ of total surface area). In YP-17, $28 \%$ of the pores are less than $1 \mathrm{~nm}, 40 \%$ are between 1 and $1.5 \mathrm{~nm}$, while the rest are greater than $1.5 \mathrm{~nm}$. $\mathrm{BF}_{4}{ }^{-}$is small enough to occupy sites in even the smallest of pores, but only, in this case, and as proposed by Chmiola et al. if it is stripped of some of its solvation shell on charging. ${ }^{7}$ Without further experiments it is difficult to test this hypothesis. However, an important observation in our experiments is that we observe the strongest influence of the electrode potential on the resonance assigned to the strongly bound anions. Charging of the carbon causes a change in the local environments of these anions, as seen by their different shifts and the shorter $\mathrm{T}_{1} \mathrm{~s}$ (on positive charging). Since these ions (or their nuclear spins) are in close proximity to electrons near the carbon Fermi level, changes in the electron density at the carbon surface (and thus on phenomena such as the ring currents) can have a significant effect on the NMR spectra of the $\mathrm{BF}_{4}^{-}$ions, as suggested in recent ex situ studies of supercapacitors. ${ }^{17}$ Changes in the average distances to which these ions approach the carbon, and also their average lifetime in these strongly bound sites, will also affect their observed chemical shifts.

In conclusion, in situ NMR experiments have been performed on Electrochemical Double Layers Capacitors (supercapacitors). The experiments allow distinct ionic coordination sites to be identified and represent a simple method with which to study the migration of ions in working supercapacitors. In the normal supercapacitor design (Figure 3), it is surprising that most of the anions in the electrolyte are located nearby the carbon, which we ascribed to the very high internal surface area of the carbon used here, the relatively non-polar solvent and limited volume of electrolyte. As expected, the anions move to the positively charged electrode on charging from -2 to $+2 \mathrm{~V}$. Loss of the strongly bound anions, that form the $1^{\text {st }}$ layer of the "double layers" in a negatively charged electrode, in a conventional model of a charged surface, is clearly visible after $<-1 \mathrm{~V}$. Any ions that are present in this layer (if any) undergo rapid exchange with the ions in more distant layers. On charging both the concentration of the anions changes, as does the nature and strength of the anion binding to the surface. The method holds much promise for the study of other supercapacitors systems and extensions to investigate the structure and dynamics of the processes that occur in a wider range of carbons/electrodes are underway. Applications of similar NMR methodologies to investigate solid - liquid interfacial structures and double-layer formation in a wide range of systems can be readily envisaged.

\section{ASSOCIATED CONTENT}

Supporting Information. Preparation of carbon films, configuration of bag cells, ex situ and in situ NMR spectroscopy methods and experiments, additional sorption experiments with $0.5 \mathrm{M}$ and $1.5 \mathrm{M}$ electrolyte, comparison between spectra of carbon films aligned perpendicular and parallel to the field, current relaxation curves of normal vs. "long" supercapacitors when a constant voltage was applied, second "long" supercapacitor result. This material is available free of charge via the Internet at http://pubs.acs.org.

\section{AUTHOR INFORMATION}

\section{Corresponding Author}

cpg27@cam.ac.uk

ACKNOWLEDGMENT. T.K. thanks the Deutscher Akademischer Austauschdienst for a postdoctoral research stipend. C.P.G. and H.W. thank NYSERDA and the EU ERC programs for support. P.S. and Y.G. would like to thank the Partner University Fund (PUF) for funding their collaborative efforts.

\section{REFERENCES}

(1) Lackner, M. A.; Manwell, J. F. Wind Eng. 2007, 31, 247

(2) Weisz, P. B. Phys. Today 2004, 57, 47.

(3) Tarascon, J. M.; Armand, M. Nature 2001, 414, 359.

(4) Simon, P.; Gogotsi, Y. Nat. Mater. 2008, 7, 845.

(5) Frackowiak, E.; Beguin, F. Carbon 2001, 39, 937.

(6) Portet, C.; Yushin, G.; Gogotsi, Y. J. Electrochem. Soc. 2008, 155 , A531.

(7) Chmiola, J.; Yushin, G.; Gogotsi, Y.; Portet, C.; Simon, P.; Taberna, P. L. Science 2006, 313, 1760.

(8) Arico, A. S.; Bruce, P.; Scrosati, B.; Tarascon, J. M.; Van Schalkwijk, W. Nat. Mater. 2005, 4, 366.

(9) Kötz, R.; Carlen, M. Electrochim. Acta 2000, 45, 2483.

(10) Levi, M. D.; Salitra, G.; Levy, N.; Aurbach, D.; Maier, J. Nat. Mater. 2009, 8, 872.

(11) Tong, Y. Y.; Rice, C.; Wieckowski, A.; Oldfield, E. J. Am. Chem. Soc. 2000, 122, 1123.

(12) Chan, K. W. H.; Wieckowski, A. J. Electrochem. Soc. $1990,137,367$.

(13) Chevallier, F.; Letellier, M.; Morcrette, M.; Tarascon, J. M.; Frackowiak, E.; Rouzaud, J. N.; Beguin, F. Electrochem. Solid State Lett. 2003, 6, A225.

(14) Key, B.; Bhattacharyya, R.; Morcrette, M.; Seznec, V.; Tarascon, J. M.; Grey, C. P. J. Am. Chem. Soc. 2009, 131, 9239.

(15) Gerald II, R. E.; Johnson, C. S.; Rathke, J. W.; Klingler, R. J.; Sandi, G.; Scanlon, L. G. J. Power Sources 2000, 89, 237.

(16) Lee, S. I.; Saito, K.; Kanehashi, K.; Hatakeyama, M.; Mitani, S.; Yoon, S. H.; Korai, Y.; Mochida, I. Carbon 2006, 44, 2578 .

(17) Deschamps, M.; Gilbert, E.; Raymundo-Pinero, E.; Azais, P.; Béguin, B.; Massiot, D. In Experimental NMR Conference Pacific Grove, California, 2011

(18) Trease, N.; Köster, T.; Wang, H.; Zhu, B.; Middlemiss, D.; Zhou, L.; Key, B.; Bhattacharyya, R.; Chen, H.; Blanc, L.; Blanc, F.; Grey, C. P. In Experimental NMR Conference Pacific Grove, California, 2011

(19) Harris, R. K.; Thompson, T. V.; Norman, P. R.; Pottage, C. Carbon 1999, 37, 1425.

(20) Gradsztajn, S.; Conard, J.; Benoit, H. Journal of Physics and Chemistry of Solids 1970, 31, 1121. 
(21) Trease, N. M.; Zhou, L.; Chang, H. J.; Zhu, B. Y.; Grey, C. P., to be submitted.

(22) Chmiola, J.; Largeot, C.; Taberna, P.-L.; Simon, P.; Gogotsi, Y. Ange. Chem., Int. Ed. 2008, 47, 3392.
(23) Cosgrove, T.; Copping, B. W.; Jarvis, R. A. J. Colloid Interface Sci. 1983, 96, 214.

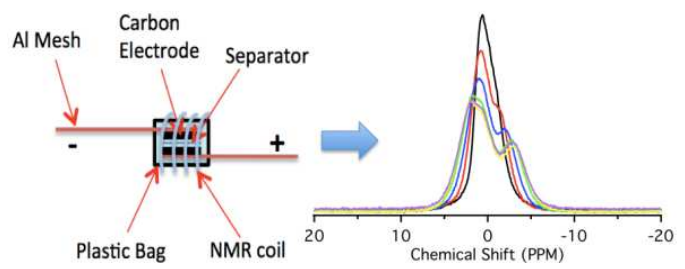

